Two- and three-dimensional visualized pathological joints from X-ray and computed tomography generated images in a patient with long-standing (inadequately treated) RA (A) and a patient with early RA (B). Overall rating (range $0-10$ ) on the VR application divided into four different professional subgroups (C); recommendations of VR application in the four different professional subgroups (D). HC, health care professionals; Boxplot explanation: Crossbars represent medians, whiskers represent 5-95 percentiles (points below the whiskers are drawn as individual points), box always extends from the 25th to 75th percentiles (hinges of the plot).

Disclosure of Interests: Philipp Klemm Consultant of: Lilly Deutschland GmbH, Arnd Kleyer Speakers bureau: Lilly Deutschland $\mathrm{GmbH}$, Consultant of: Lilly Deutschland $\mathrm{GmbH}$, Grant/research support from: Lilly Deutschland $\mathrm{GmbH}$, Koray Tascilar: None declared, Louis Schuster: None declared, Timo Meinderink: None declared, Florian Steiger: None declared, Uwe Lange: None declared, Ulf Müller-Ladner: None declared, Johannes Knitza Speakers bureau: Lilly Deutschland GmbH, Philipp Sewerin Speakers bureau: Lilly Deutschland GmbH, Paid instructor for: Lilly Deutschland $\mathrm{GmbH}$, Johanna Mucke Consultant of: Lilly Deutschland $\mathrm{GmbH}$, Alexander Pfeil Speakers bureau: Lilly Deutschland GmbH, Paid instructor for: Lilly Deutschland $\mathrm{GmbH}$, Consultant of: Lilly Deutschland $\mathrm{GmbH}$, Georg Schett: None declared, Fabian Hartmann Consultant of: Lilly Deutschland $\mathrm{GmbH}$, Axel Hueber Consultant of: Lilly Deutschland GmbH, Grant/ research support from: Lilly Deutschland $\mathrm{GmbH}$, David Simon Speakers bureau: Lilly Deutschland $\mathrm{GmbH}$, Paid instructor for: Lilly Deutschland $\mathrm{GmbH}$, Consultant of: Lilly Deutschland $\mathrm{GmbH}$, Grant/research support from: Lilly Deutschland $\mathrm{GmbH}$

DOI: 10.1136/annrheumdis-2021-eular.1452

\section{POS1493-HPR IMPACT OF THE EULAR HCP CORE COMPETENCIES ON RHEUMATOLOGY PHYSIOTHERAPISTS INTHE UK: SURVEY RESULTS}

W. J. Gregory ${ }^{1,2}$, S. Burchett ${ }^{3}$, C. Mccrum ${ }^{4,5} .{ }^{1}$ Salford Royal NHS Foundation Trust, Rheumatology Directorate, Manchester, United Kingdom; ${ }^{2}$ Manchester Metropolitan University, Department of Health Professionals; Faculty of Health, Psychology and Social Care, Manchester, United Kingdom; ${ }^{3}$ East Sussex Healthcare NHS Trust, Information Management and Performance, Hastings, United Kingdom; ${ }^{4}$ East Sussex Healthcare NHS Trust, Physiotherapy Department, Hastings, United Kingdom; ${ }^{5}$ University Of Brighton, Research Centre for Healthcare Professionals, Brighton, United Kingdom

Background: A European Alliance of Associations for Rheumatology (EULAR) initiative in 2019 saw the first-ever publication of Core Competencies for Health Care Professionals (HCPs) working in Rheumatology (Edelaar et al 2019). This document sets the tone for how HCPs in Rheumatology should be working. One of the listed research agenda items created as a part of this project was to define discipline-specific competencies related to each of the HCPs unique roles in the multidisciplinary team.

Objectives: In response to this call for discipline-specific application, a recent national survey of physiotherapists working in rheumatology in the UK included a section looking at the comfort these clinicians feel in the day-to-day application of these Core Competencies.

Methods: In late 2019, an internet-based survey was emailed, and shared via other digital platforms, aiming to target all UK-based rheumatology physiotherapists. Other areas were covered and have been published (Gregory, Burchett and McCrum 2021), but there are unpublished data from Question 8 on this survey which involved listing the EULAR HCP Core Competencies and asking responders to rate on a 5-point Likert scale their comfort with these statements in relation to their day-to-day practice.

Results: Ninety-seven UK-based physiotherapists working at least some of their job in rheumatology completed the survey. Overall the EULAR HACP core competency statements with the highest scores were statements 2 and 5 ; those statements with the lowest comfort response were statements 4 and 6 .

Statement 2 relates to assessment and statement 5 to non-pharmacological management; it is in line with the traditional physiotherapy job role that these are the two areas identified by survey responders as their strongest areas.

Statement 4 relates to pharmacological management, and as this is not a formal part of expected specialist rheumatology physiotherapist job role at banding levels below band 8, this result was lower level of comfort probably to be expected. Statement 6 relates to patient education and whilst this is clearly a big part of the physiotherapist role, we expect the lower score here represents respondents awareness that broader disease education may sit better with other members of the rheumatology multi-disciplinary team.

Conclusion: Written for all HCPs, the competency statements do show less comfort on this survey of physiotherapists with regards to less profession-specific statements, namely medication management and disease education. Team working means these areas will be picked up by other rheumatology HCPs.

Generally there is a good amount of familiarity with and comfort in application of these new core competencies. An alternative conclusion is that the EULAR working group creating the competencies achieved a strong understanding of the HCP roles and the competencies are hence seen to fit well in this survey. As per the concluding statements of the 2019 EULAR core competencies document, there does remain a requirement to work on profession specific competencies in rheumatology.

REFERENCES:

[1] Edelaar L, Nikiphorou E, Fragoulis GE, et al. 2019 EULAR recommendations for the generic core competences of health professionals in rheumatology. Annals of the Rheumatic Diseases 2020;79:53-60.

[2] Gregory, W.J., Burchett, S. and McCrum, C. (2021), National survey of the current clinical practices of the UK rheumatology physiotherapists: A short report. Musculoskeletal Care. https://doi.org/10.1002/msc.1516

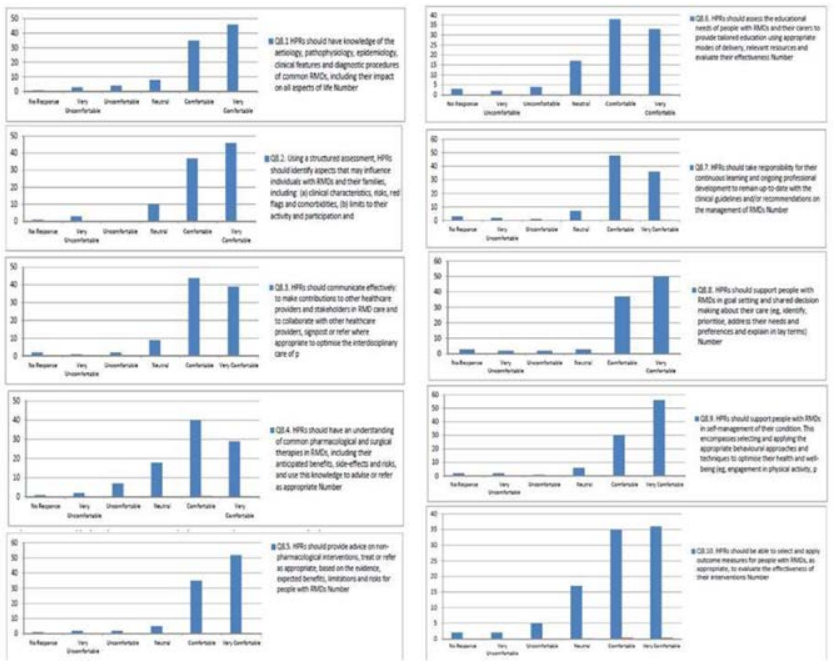

Disclosure of Interests: William J. Gregory Speakers bureau: Speaker fees from Novartis and Abbvie., Consultant of: Advisory boards for Pfizer and Novartis., Sharon Burchett: None declared, Carol McCrum Speakers bureau: Speaker fees from Novartis

DOI: 10.1136/annrheumdis-2021-eular.2808

\section{HPR Interdisciplinary research}

\section{POS1494-HPR THE COLLABORATION OF RHEUMATOLOGY- DERMATOLOGY IN THE EVALUATION OF RHEUMATIC DISEASES PATIENTS: EXPERIENCE IN A UNIVERSITY HOSPITAL}

G. Figueroa-Parra ${ }^{1}$, A. Moreno-Salinas ${ }^{1}$, C. M. Gamboa-Alonso ${ }^{1}$, M. A. Villarreal-Alarcón ${ }^{1}$, D. Á. Galarza-Delgado ${ }^{1}{ }^{1}$ Hospital Universitario Dr. José Eleuterio González, Universidad Autónoma de Nuevo León, Servicio de Reumatología, Monterrey, Mexico

Background: Dermatological manifestations are not rare in patients with rheumatic diseases (RD). Multidisciplinary management and direct interaction between these disciplines are essential. According to Dermatology-Rheumatology clinics, most diagnoses evaluated are systemic lupus erythematosus (SLE) and rheumatoid arthritis (RA), with dermatitis being the most common manifestation. It is important to be aware that skin problems in RD patients are not always related to the underlying condition(1). Nowadays, there is significant evidence to support the manifold advantages of the joint dermatology-rheumatology clinics, including improved quality of care for patients and multidisciplinary training for new physicians(2). This ongoing trend is intended to highlight the important interaction between specialties that treat overlapping conditions, and it has been incorporated in academic health centers to give a comprehensive approach to patients.

Objectives: Our purpose was to describe the collaboration between the Rheumatology and Dermatology services during the evaluation of RD patients.

Methods: An observational, retrospective study was performed in the Rheumatology Service of the University Hospital "Dr. Jose Eleuterio Gonzalez" in Monterrey, Mexico, between March 2019 and February 2020. All the patients with a Rheumatology or Dermatology consultation requested were included (hospitalized and outpatients). Demographic (age, gender, baseline diagnosis), the reason for consultation, specialty requested, type of treatment, final diagnoses, and agreement in final diagnosis were registered. Results are shown in descriptive statistics. 